\title{
Convection-enhanced delivery of methotrexate-loaded maghemite nanoparticles
}

This article was published in the following Dove Press journal:

International Journal of Nanomedicine

2 August 201I

Number of times this article has been viewed

\author{
Enav Corem-Salkmon' \\ Zvi Ram ${ }^{2,3}$ \\ Dianne Daniels ${ }^{3,4}$ \\ Benny Perlstein' \\ David Last ${ }^{4}$ \\ Sharona Salomon ${ }^{4}$ \\ Gregory Tamar ${ }^{4}$ \\ Ran Shneor ${ }^{4}$ \\ David Guez ${ }^{4}$ \\ Shlomo Margel' \\ Yael Mardor ${ }^{3,4}$ \\ 'The Institute of Nanotechnology \\ and Advanced Materials, Department \\ of Chemistry, Bar-llan University, \\ Ramat-Gan, ${ }^{2}$ Department of \\ Neurosurgery, Tel Aviv Medical \\ Center, Tel Aviv, ${ }^{3}$ Sackler Faculty of \\ Medicine, Tel Aviv University, Tel Aviv, \\ ${ }^{4}$ Advanced Technology Center, Sheba \\ Medical Center, Tel-Hashomer, Israel
}

Correspondence: Yael Mardor The Advanced Technology Center, Sheba Medical Center, Tel-Hashomer, 52621 , Israel

Tel +972 35302993

Fax +97235303146

Email yael.mardor@sheba.health.gov.il
Abstract: Convection-enhanced delivery (CED) is a novel approach for delivering drugs directly into brain tumors by intracranial infusion, enabling the distribution of high drug concentrations over large tissue volumes. This study was designed to present a method for binding methotrexate (MTX) to unique crystalline, highly ordered and superparamagnetic maghemite nanoparticles via human serum albumin (HSA) coating, optimized for CED treatments of gliomas. Naked nanoparticles and HSA- or polyethylene glycol (PEG)-coated nanoparticles with/without MTX were studied. In vitro results showed no toxicity and a similar cell-kill efficacy of the MTX-loaded particles via HSA coating to that of free MTX, while MTX-loaded particles via PEG coating showed low efficacy. In vivo, the PEG-coated nanoparticles provided the largest distributions in normal rat brain and long clearance times, but due to their low efficacy in vitro, were not considered optimal. The naked nanoparticles provided the smallest distributions and shortest clearance times. The HSA-coated nanoparticles (with/without MTX) provided good distributions and long clearance times (nearly $50 \%$ of the distribution volume remained in the brain 3 weeks post treatment). No MTX-related toxicity was noted. These results suggest that the formulation in which HSA was bound to our nanoparticles via a unique precipitation method, and MTX was bound covalently to the HSA, could enable efficient and stable drug loading with no apparent toxicity. The cell-kill efficacy of the bound MTX remained similar to that of free MTX, and the nanoparticles presented efficient distribution volumes and slow clearance times in vivo, suggesting that these particles are optimal for CED.

Keywords: convection-enhanced delivery, nanoparticles, methotrexate, magnetic resonance imaging, rat brain

\section{Introduction}

Malignant primary brain tumors, especially the highly malignant recurrent glioblastoma multiforme (GBM), are fatal within months of diagnosis. Chemotherapy confers no significant survival advantage, in part due to the poor penetration of most chemotherapeutic drugs across the blood-brain barrier (BBB). Convection-enhanced delivery (CED) is a novel approach to deliver drugs directly into brain tumors. It is based on delivering a continuous infusion of drugs via intracranial catheters, enabling the convective distribution of high drug concentrations over large volumes of tissue while avoiding systemic toxicity. ${ }^{1-4}$

Efficient CED formation depends on various physical/physiological parameters. ${ }^{5,6}$ Previous CED-based clinical trials showed a significant diversity in the extent of convection among patients and drugs. We have previously shown that CED formation/ extent may be significantly improved by increasing infusate viscosities. ${ }^{7}$ Efficient CED 
is currently limited to small molecules $(<200 \mathrm{kDa})$. We have recently demonstrated the application of our increased efficacy methodologies to enable efficient CED of maghemite nanoparticles in a normal rat brain model. ${ }^{8}$ The authors have also established the validity of using magnetic resonance imaging (MRI) for depicting the distribution of the convected maghemite nanoparticles in the brain. This study also demonstrated the long clearance time of the maghemite nanoparticles from the brain (weeks to months) with no evidence of toxicity.

Methotrexate (MTX) is a folic acid analog used as a chemotherapeutic agent. As folate receptors are over expressed on the cell membranes of many types of cancer cells, MTX is one of the most widely used drugs for the treatment of many forms of cancer, including tumors of the brain, breast, ovaries, and several leukemias. However, MTX is limited by its low solubility, dose-related toxicity, lack of selectivity, rapid diffusion throughout the body, short half-life in the bloodstream, and drug resistance by target cells. ${ }^{9,10}$ Recent literature indicates increasing interest in binding MTX to nanoparticles to alter its pharmacokinetic behavior, enhance tumor targeting, reduce toxicity, and overcome drug-resistance mechanisms. ${ }^{1-14}$ In this study we used the combination of nanoparticles with $\mathrm{CED}$, thus avoiding the main limitation introduced by systemic administration.

Magnetic nanoparticles are considered to be spherical particles with magnetic properties in sizes ranging from a few $\mathrm{nm}$ to approximately $100 \mathrm{~nm}$. These particles, because of their spherical shape, large surface area and magnetic properties, may have a wide range of potential applications. ${ }^{15-21}$ Magnetic nanoparticles that have been approved by the FDA are Feridex and Combidex, used as MRI contrast agents. These are prepared by reacting ferrous and ferric salts in the presence of appropriate surfactants (or polymers) in an aqueous phase under severe basic conditions, producing a broad size distribution (considered a potential source of toxicity). Particles prepared this way often suffer from lack of stability due to agglomeration, and the technology to covalently bind bioactive reagents (ie, proteins) to their surface, particularly to the smallest available particles, is still obscure. Furthermore, since these nanoparticles are prepared under basic conditions, the encapsulation of sensitive bioactive reagents, eg, proteins, within the nanoparticles for drug delivery and controlled-release applications is not efficient due to denaturation of the proteins. Other highly investigated superparamagnetic nanoparticles, MION (monocrystalline iron oxide nanocompounds and AMI-25 (Advanced Magnetics, Inc, Cambridge, MA), ${ }^{22,23}$ also prepared similarly by the interaction of ferrous and ferric salts in an aqueous phase under basic conditions, possess similar limitations and are not yet suitable for clinical use.

The authors have recently prepared and characterized new uniform magnetic maghemite $\left(\gamma-\mathrm{Fe}_{2} \mathrm{O}_{3}\right)$ nanoparticles, ${ }^{23}$ formed via controlled nucleation and then the growth of thin films of maghemite onto gelatin/iron oxide nuclei. These particles can be prepared in sizes of 15-80 nm. They are biodegradable, nontoxic and have a narrow size distribution. Their preparation is simple and can be performed close to physiological $\mathrm{pH}$, with a yield of almost $100 \%$. These nanoparticles are also superparamagnetic, enabling real-time imaging with MRI. Using these nanoparticles, biocompatible, stabilized particles containing various functional groups are prepared by coating with a variety of polymers including proteins, polysaccharides such as dextran, and polyethylene glycols. The functional groups of these coatings can then be used for the covalent binding of bioactive reagents such as drugs, proteins, antibodies and enzymes, to the surface of these maghemite nanoparticles. ${ }^{24-26}$

Since maghemite nanoparticles have been shown to provide increased uptake in cancer cells versus normal cells, ${ }^{27}$ and since human serum albumin (HSA) and polyethylene glycol (PEG) have been shown to increase the intake of MTX into cancer cells, ${ }^{12,28,29}$ this study focuses on developing a methodology to bind MTX, a well-proven anti-tumor agent active in GBM, via HSA to the magnetic nanoparticles. The uptake of the drug-loaded particles and the efficacy of the drug-loaded particles versus the efficacy of the free drug were studied in vitro, followed by in vivo CED experiments to study the efficacy of distribution and clearance patterns of the nanoparticles in the brain.

The efficient CED of nanoparticles may enable the use of drugs and/or drug carriers that until now were considered inappropriate for convection treatment. Nanoparticles as drug carriers may enable the real-time depiction of particle distribution in the tissue, provide slow drug release, enable the delivery of larger therapeutic agents, and allow targeted drug delivery. ${ }^{30-32}$

\section{Materials and methods}

\section{In vitro and in vivo experimental outline}

To obtain methotrexate-loaded maghemite nanoparticles, which are both effective in treating cancer cells, yet nontoxic to a normal brain, and taking into account the fact that animal brain tumor models do not simulate human tumors as regards consistency (and therefore are suboptimal for convectionbased studies), the experiments were performed separately 
in vitro and in vivo. The in vitro experiments were designed to establish the anti-tumor efficacy of the drug-loaded particles and confirm that the vehicles (the nonloaded particles) were nontoxic. In these experiments, 9L gliosarcoma cells were incubated with the drug-loaded particles and controls for 48 hours. Following the incubation period, the cells were counted and the cell kill of each treatment was calculated. Once the drug-loaded particles were shown to be effective and the nonloaded particles were shown to be nontoxic, they were subjected to further studies in vivo.

An additional in vitro experiment was designed to determine the efficacy of the penetration of the nanoparticles into the cells, using MRI. In this experiment the cells were incubated for 24 hours with the nanoparticles. The cells were then rinsed and a pellet was prepared. Pellet vials were placed in the MRI together with calibration vials containing free nanoparticles at different concentrations. The $\gamma-\mathrm{Fe}_{2} \mathrm{O}_{3}$ concentration of the pellets was determined by comparing the contrast of the pellet vials and the calibration vials, as depicted in the magnetic resonance (MR) images.

The in vivo experiments were designed to study the distribution efficacy of the different particles in normal rat brains, to assess the clearance time from the brain, and to assess the toxicity to a normal brain. The tested solutions were infused into the rats' brains through an intracranial catheter. The rats were scanned by MRI immediately after the infusion and then once a week, and thereafter for a period of 3 weeks. In addition, the rats were weighed once a week. The distribution efficacy was determined from the volumes of distribution, calculated from the MR images acquired immediately post treatment. The clearance time from the brain was determined by following the changes in the volume of distribution as a function of time, throughout the 3-week follow-up. Toxicity was determined by survival and weight gain throughout the 3-week follow-up.

\section{Materials}

Methotrexate (MTX), glycine, divinyl sulfone (DVS), triethylamine (TEA), dimethyl sulfoxide (DMSO), $\mathrm{FeCl}_{2}$, $\mathrm{NaNO}_{3}$, potassium persulfate, 1-ethyl-3-(3-dimethylaminopropyl) carbodiimide (EDC), N-hydroxysulfosuccinimide (sulfo NHS), $\mathrm{NaOH}$, gelatin (from porcine skin), human serum albumin (HSA), polyethylene glycol (PEG, MW 400), PEG (MW 400) methacrylate (PEGMA), PEG dimethacrylate (PEGDMA) and amino terminated PEGMA ( $\mathrm{NH}_{2}$ PEGMA) were all purchased from Sigma (Rehovot, Israel). Salts for buffers were purchased from Bio-Lab Ltd (Jerusalem, Israel). Formaldehyde was purchased from
Gadot Biochemical Industries, Ltd (Haifa Bay, Israel). Water was purified by passing deionized water through an Elgastat Spectrum reverse osmosis system (Elga Ltd, High Wycombe, UK).

\section{Synthesis of the maghemite nanoparticles $\left(\gamma-\mathrm{Fe}_{2} \mathrm{O}_{3}\right)$}

Maghemite nanoparticles $\left(\gamma-\mathrm{Fe}_{2} \mathrm{O}_{3}\right)$ of narrow size distribution were prepared by nucleation followed by the controlled growth of iron oxide thin films onto the gelatin/iron oxide nuclei, as previously described. ${ }^{29}$ Briefly, $\gamma-\mathrm{Fe}_{2} \mathrm{O}_{3}$ of $19.8 \pm 4.7 \mathrm{~nm}$ dry diameter were prepared by adding a $\mathrm{FeCl}_{2}$ aqueous solution (10 mmol/5 mL in $0.1 \mathrm{~N} \mathrm{HCl}$ ) to $80 \mathrm{~mL}$ of an aqueous solution containing $240 \mathrm{mg}$ of porcine gelatin, followed by the addition of a $\mathrm{NaNO}_{3}$ solution $\left(7 \mathrm{mmol} / 5 \mathrm{~mL}\right.$ in $\left.\mathrm{H}_{2} \mathrm{O}\right)$. After a reaction time of 10 minutes, a $\mathrm{NaOH}$ aqueous solution $(1 \mathrm{~N})$ was added until a $\mathrm{pH}$ of 9.5 was obtained. This procedure was repeated four more times. During the entire procedure, the aqueous suspension was agitated at $60^{\circ} \mathrm{C}$ and kept in an inert environment. The formed $\gamma-\mathrm{Fe}_{2} \mathrm{O}_{3}$ nanoparticles were then washed from excess reagents with $\mathrm{H}_{2} \mathrm{O}$ using magnetic columns.

\section{Physical adsorption of HSA onto the maghemite nanoparticles $\left(\gamma-\mathrm{Fe}_{2} \mathrm{O}_{3} \sim \mathrm{HSA}\right)$ by precipitation}

Ten milligrams of HSA was added to $50 \mathrm{~mL}$ of the $\gamma-\mathrm{Fe}_{2} \mathrm{O}_{3}$ nanoparticles dispersed in water $(2 \mathrm{mg} / \mathrm{mL})$. The reaction mixture was then shaken at $\mathrm{pH} 9.5$ and $60^{\circ} \mathrm{C}$ for 24 hours, and then cooled gradually to room temperature. The obtained $\gamma-\mathrm{Fe}_{2} \mathrm{O}_{3} \sim \mathrm{HSA}$ nanoparticles ( $\sim$ is a symbol for the HSA physical coating obtained by precipitation) were then washed from excess HSA with phosphate-buffered saline by magnetic columns.

\section{Polymerization of polyethylene glycol acrylate derivatives on the surface of the maghemite nanoparticles $\left(\gamma-\mathrm{Fe}_{2} \mathrm{O}_{3} \sim \mathrm{PEG}\right)$}

Polymerization of PEGMA monomers on the surface of the maghemite nanoparticles was accomplished by mixing $25 \mathrm{~mL}$ of the maghemite nanoparticles dispersed in a bicarbonate buffer $(0.1 \mathrm{M}, \mathrm{pH} 8.3,4 \mathrm{mg} / \mathrm{mL})$ with $0.35 \mathrm{~mL}$ of PEGMA, $0.05 \mathrm{~mL}$ of PEG dimethacrylate (PEGDMA), $0.1 \mathrm{~mL}$ of NH2PEGMA, and $24 \mathrm{mg}$ of potassium persulfate dissolved in $25 \mathrm{~mL}$ of a bicarbonate buffer $(0.1 \mathrm{M}, \mathrm{pH} 8.3)$. For the polymerization process, the above mixture was shaken at $73^{\circ} \mathrm{C}$ for 4 hours. The formed $\gamma-\mathrm{Fe}_{2} \mathrm{O}_{3} \sim \mathrm{PEG}-\mathrm{NH}_{2}$ particles were then washed from excess monomers by magnetic columns. 


\section{Physical conjugation of methotrexate to the HSA-coated nanoparticles $\left(\gamma-\mathrm{Fe}_{2} \mathrm{O}_{3} \sim \mathrm{HSA} \sim \mathrm{MTX}\right)$}

MTX was physically conjugated to the HSA coated nanoparticles, $\gamma-\mathrm{Fe}_{2} \mathrm{O}_{3} \sim \mathrm{HSA}$, by adding $1 \mathrm{mg}$ of MTX dissolved in $1 \mathrm{~mL}$ of DMSO to $20 \mathrm{~mL}$ of the nanoparticle dispersion in PBS $(1 \mathrm{mg} / \mathrm{mL})$. The reaction mixture was then shaken at room temperature for 18 hours. The obtained $\gamma-\mathrm{Fe}_{2} \mathrm{O}_{3} \sim \mathrm{HSA} \sim \mathrm{MTX}$ nanoparticles were then washed from excess MTX with PBS (0.1 M, pH 7.3) by magnetic columns. Higher concentrations of MTX were obtained by increasing the initial MTX concentration.

\section{Covalent binding of MTX} to the HSA-coated and PEG-coated nanoparticles $\left(\gamma-\mathrm{Fe}_{2} \mathrm{O}_{3} \sim \mathrm{HSA}-\mathrm{MTX}\right.$, $\left.\gamma-\mathrm{Fe}_{2} \mathrm{O}_{3} \sim \mathrm{PEG}-\mathrm{MTX}\right)$

MTX was covalently conjugated to the HSA-coated nanoparticles, $\gamma$ - $\mathrm{Fe}_{2} \mathrm{O} \sim \mathrm{HSA}$. In a typical experiment, $5 \mathrm{mg}$ of MTX dissolved in $2.5 \mathrm{~mL}$ of DMSO was added to $2.5 \mathrm{mg}$ of 1-ethyl-3-(3-dimethylaminopropyl) carbodiimide (EDC) and $5 \mathrm{mg}$ sulfo-NHS dissolved in $2.5 \mathrm{~mL}$ of water. The mixture was then shaken at room temperature for 15 minutes. Twenty milliliters of the HSA-coated nanoparticles $\left(\gamma-\mathrm{Fe}_{2} \mathrm{O}_{3} \sim \mathrm{HSA}\right.$, $1 \mathrm{mg} / \mathrm{mL}$ ) were then added and the mixture was shaken at room temperature for 1 hour, after which the nanoparticles were washed from excess reagents by magnetic columns. In a similar way MTX was conjugated to the terminal $\mathrm{NH}_{2}$ groups of the $\gamma-\mathrm{Fe}_{2} \mathrm{O}_{3} \sim \mathrm{PEG}-\mathrm{NH}_{2}$ nanoparticles. Higher concentrations of MTX were obtained by increasing the initial MTX concentration.

\section{Determination of the bound HSA concentration}

The concentration of HSA bound to the $\gamma-\mathrm{Fe}_{2} \mathrm{O}_{3}$ nanoparticles was determined by measuring the unbound proteins using the Bradford assay ${ }^{33,34}$ and subtracting it from the initial concentration. The reported values are an average of at least three measurements of each sample. The binding yield was calculated by multiplying the ratio of the concentration of the bound MTX to the initial concentration by 100 .

\section{Determination of the bound MTX concentration}

The concentration of MTX bound to the $\gamma-\mathrm{Fe}_{2} \mathrm{O}_{3}$ nanoparticles was indirectly determined by measuring the absorbance of the unbound drug at $303 \mathrm{~nm}$. The binding yield was calculated by multiplying the ratio of the concentration of the bound MTX to the initial concentration by 100 .

\section{Cell culture procedures}

9L gliosarcoma cells, which overexpress the folate receptor, were maintained at $37^{\circ} \mathrm{C}$ and $5 \% \mathrm{CO}_{2}$ in Dulbecco's Modified Eagle's Medium (DMEM) (Biological Industries, Kibbutz Beit Haemek, Israel) enriched with $10 \%$ FCS and $1 \%$ penicillin/streptomycin and subcultured twice a week. The cells were plated at a density of $6 \times 10^{4}$ per well in 24 well plates for the cell-kill experiments and at $1 \times 10^{6}$ per $10 \mathrm{~cm}$ plates for the in vitro MRI experiments. The cells were incubated for 24 hours and then treated with the indicated concentration of the therapeutic agents or with the vehicles. Treatment duration was 24 hours for the in vitro MRI experiments and 48 hours for the cell-kill experiments.

\section{In vitro cell-kill experiments}

9L cells were treated with the therapeutic agent or with the vehicle for 48 hours. The concentration of the particles was $0.2 \mathrm{mg} / \mathrm{mL}$ and the concentration of the bound MTX was $1 \mu \mathrm{g} / \mathrm{mL}$. The effect of the treatment on cell growth was determined by direct counting of the cells collected from each well using a trypan blue assay. To calculate the average percentage of viable cells, the number of cells counted for each treatment was divided by the number of cells in the control group. The experiment was performed in quadruplicate.

\section{In vitro $M R I$ experiments}

In order to determine whether the nanoparticles penetrated the 9L cells efficiently, 9L cells were incubated with $\gamma-\mathrm{Fe}_{2} \mathrm{O}_{3}$ nanoparticles and $\gamma-\mathrm{Fe}_{2} \mathrm{O}_{3} \sim \mathrm{HSA}$ nanoparticles $(0.2 \mathrm{mg} / \mathrm{mL})$ for 24 hours. A pellet was prepared from each of the two particle types. The pellet was rinsed twice with PBS and placed in $1.5 \mathrm{~mL}$ vials. Calibration vials were prepared with free $\gamma-\mathrm{Fe}_{2} \mathrm{O}_{3}$ nanoparticles at concentrations ranging between $0.06-6.0 \mathrm{mg} / \mathrm{mL}$. The two-pellet vials were placed in the MRI coil together with the calibration vials to assess the $\gamma-\mathrm{Fe}_{2} \mathrm{O}_{3}$ concentration in the pellets.

\section{In vivo CED experiments}

The study was performed in accordance with the guidelines of The Animal Care and Use Committee of Sheba Medical Center, which is recognized by the Israeli authorities for animal experimentation. The CED of nanoparticles was performed into the striatum of normal Sprague-Dawley male rats $(280-320 \mathrm{~g})$ under full anesthesia at a rate of $4 \mu \mathrm{L} / \mathrm{min}$ over 15 minutes. Immediately after the infusion the rats 
were scanned by gradient-echo MRI for assessment of the nanoparticle distribution, and by T2-weighted MRI for the depiction of procedure-related toxicity. The rats were scanned and weighed once a week for an additional period of 3 weeks for assessment of the toxicity and clearance time of the nanoparticles.

Thirteen rats were treated with CED of $\gamma-\mathrm{Fe}_{2} \mathrm{O}_{3} \sim \mathrm{PEG}$, 11 rats with $\gamma-\mathrm{Fe}_{2} \mathrm{O}_{3} \sim \mathrm{HSA}, 14$ rats with $\gamma-\mathrm{Fe}_{2} \mathrm{O}_{3} \sim \mathrm{HSA}-\mathrm{MTX}$, and 11 rats with $\gamma-\mathrm{Fe}_{2} \mathrm{O}_{3}$.

\section{CED procedure}

Under full anesthesia, a midline scalp incision was made to identify the bregma. A 1-mm burr hole was made in the right region of the skull, $2 \mathrm{~mm}$ lateral and $3 \mathrm{~mm}$ posterior to the bregma. A 30-gauge needle attached to a $1000 \mu \mathrm{L}$ syringe (Gastight; Hamilton Company, Reno, NV) was placed stereotactically $5.5 \mathrm{~mm}$ deep in the rat striatum. The infusion was performed using a BASi syringe pump (Bioanalytical Systems Inc, West Lafayette, IN) at a rate of $4 \mu \mathrm{L} / \mathrm{min}$ for 15 minutes.

\section{Imaging protocol}

Gradient-echo and T2-weighted MR images were acquired using a 1.5T GE MRI system and the standard phased-array GE head-coil. Gradient-echo MRI were acquired with a $512 \times 512$ matrix, $16 \times 12 \mathrm{~cm}^{2}$ field of view, repetition time of $425 \mathrm{~ms}$, echo time of $15 \mathrm{~ms}$, a flip angle of $15^{\circ}$ and $2 \mathrm{~mm}$ slices with no gap. T2-weighted fast spin echo MRI were

acquired with a $512 \times 512$ matrix, $16 \times 12 \mathrm{~cm}^{2}$ field of view, repetition time of $5,500 \mathrm{~ms}$, echo time of $80.2 \mathrm{~ms}$, and $2 \mathrm{~mm}$ slices with no gap.

\section{Calculation of maghemite nanoparticle distribution area}

The area (in $\mathrm{mm}^{2}$ ) of the infusate distribution was calculated from the gradient-echo MR images. Regions of interest (ROIs) were defined over the entire signal void region in each slice (excluding the ventricles). The number of pixels in the ROIs were counted and multiplied by the volume of a single pixel. Data are presented as mean \pm standard deviation (SD).

\section{Results}

MRI for assessment of $\gamma-\mathrm{Fe}_{2} \mathrm{O}_{3}$ and $\gamma-\mathrm{Fe}_{2} \mathrm{O}_{3} \sim \mathrm{HSA}$ penetration into the cells: Pellets prepared from 9L cells incubated with $\gamma$ - $\mathrm{Fe}_{2} \mathrm{O}_{3}$ and $\gamma-\mathrm{Fe}_{2} \mathrm{O}_{3} \sim \mathrm{HSA}$ nanoparticles were placed in the MRI together with calibration vials containing free nanoparticles at concentrations ranging between $0.06-6.0 \mathrm{mg} / \mathrm{mL}$. The MR images (Figure 1) showed that both pellets consisted of $0.2 \pm 0.075 \mathrm{mg} / \mathrm{mL} \gamma-\mathrm{Fe}_{2} \mathrm{O}_{3}$.

\section{In vitro $9 \mathrm{~L}$ cell-kill experiments}

9L cells were treated with $\gamma-\mathrm{Fe}_{2} \mathrm{O}_{3} \sim \mathrm{PEG}, \gamma-\mathrm{Fe}_{2} \mathrm{O}_{3} \sim$ PEGMTX, $\gamma-\mathrm{Fe}_{2} \mathrm{O}_{3} \sim \mathrm{HSA}$ and $\gamma-\mathrm{Fe}_{2} \mathrm{O}_{3} \sim \mathrm{HSA}-\mathrm{MTX}$ for 48 hours. The $\gamma-\mathrm{Fe}_{2} \mathrm{O}_{3} \sim \mathrm{HSA}$ particles showed no toxicity: $2 \% \pm 2 \%$ cell kill. The $\gamma-\mathrm{Fe}_{2} \mathrm{O}_{3} \sim \mathrm{HSA}-\mathrm{MTX}$ showed a similar efficacy to that of free MTX: $63 \% \pm 6 \%$ and $77 \% \pm 4 \%$ respectively. The

A

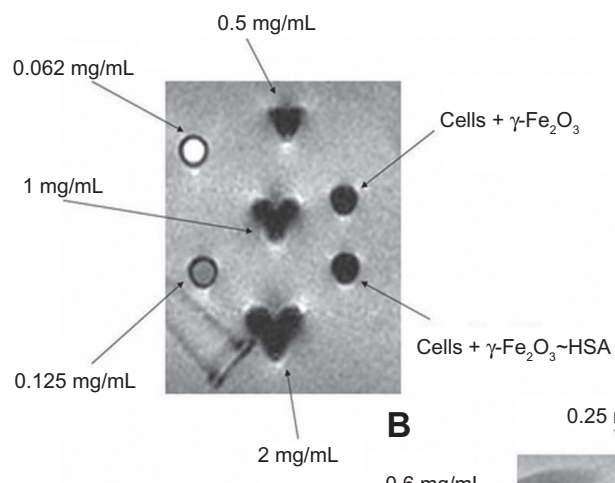

C

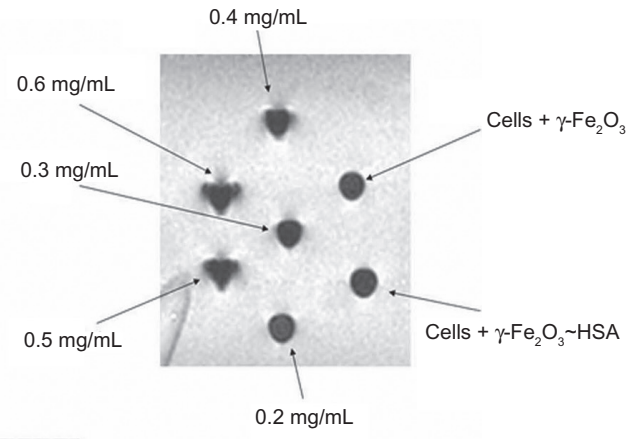

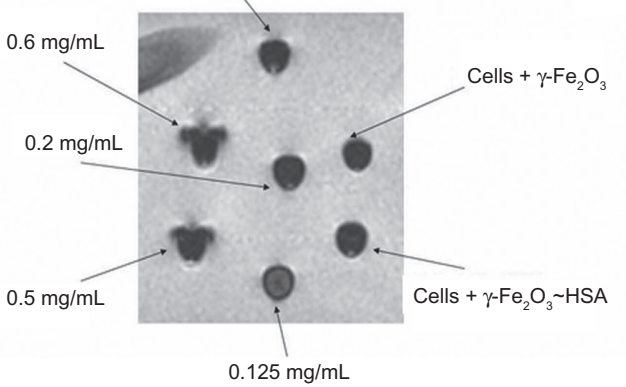

Figure I Gradient-echo magnetic resonance images of pellets prepared from $9 \mathrm{~L}$ cells incubated with $0.2 \mathrm{mg} / \mathrm{mL} \gamma-\mathrm{Fe}_{2} \mathrm{O}_{3}$ and $\gamma$-Fe $\mathrm{O}_{3} \sim \mathrm{HSA}$ and calibration vials containing free maghemite nanoparticles at concentrations ranging from $0.06 \mathrm{mg} / \mathrm{mL}$ to $6.0 \mathrm{mg} / \mathrm{mL}$. The magnetic resonance imaging shows that both pellets consisted of $0.2 \pm 0.075 \mathrm{mg} / \mathrm{mL} \gamma-\mathrm{Fe} \mathrm{O}_{3}$. 
$\gamma-\mathrm{Fe}_{2} \mathrm{O}_{3} \sim \mathrm{PEG}$ were marginal in means of toxicity: $6 \% \pm 4 \%$, but the efficacy of the $\gamma-\mathrm{Fe}_{2} \mathrm{O}_{3} \sim$ PEG-MTX was relatively low with a wide range of variability: $40 \% \pm 19 \%$.

\section{In vivo experiments}

The highest average distribution volume, as calculated from the MR images acquired immediately post treatment, was obtained by the CED of $\gamma-\mathrm{Fe}_{2} \mathrm{O}_{3} \sim$ PEG: $118.1 \pm 11.3 \mathrm{~mm}^{3}$ (Figure 2). However, this volume was not significantly higher than the volume of distribution of the $\gamma-\mathrm{Fe}_{2} \mathrm{O}_{3} \sim \mathrm{HSA}: 103.6 \pm 13.1 \mathrm{~mm}^{3}$. The distribution of the $\gamma-\mathrm{Fe}_{2} \mathrm{O}_{3} \sim \mathrm{HSA}-\mathrm{MTX}$ nanoparticles was lower than that of the particles without the drug: $80.2 \pm 6.9 \mathrm{~mm}^{3}$. This difference was not significant statistically, although the difference between the $\gamma-\mathrm{Fe}_{2} \mathrm{O}_{3} \sim$ PEG and the $\gamma-\mathrm{Fe}_{2} \mathrm{O}_{3} \sim \mathrm{HSA}-\mathrm{MTX}$ nanoparticles was significant $(P<0.007$, unpaired $t$ test), suggesting that the drug may somewhat impair the efficacy of convection. The naked particles, $\gamma$ - $\mathrm{Fe}_{2} \mathrm{O}_{3}$, showed the lowest volumes of distributions: $36.1 \pm 4.4 \mathrm{~mm}^{3}$. These volumes were significantly lower than all the coated particles $(P<0.0002$ versus $\gamma-\mathrm{Fe}_{2} \mathrm{O}_{3} \sim$ PEG, $P<0.0008$ versus $\gamma-\mathrm{Fe}_{2} \mathrm{O}_{3} \sim \mathrm{HSA}$ and $P<0.0003$ versus $\gamma$ - $\mathrm{Fe}_{2} \mathrm{O}_{3} \sim \mathrm{HSA}-\mathrm{MTX}$, Mann-Whitney test. ${ }^{35}$ ). Examples of the MRI-depicted distributions as a function of time are shown in Figure 3.

The rats were weighed once a week for the duration of the study and the average weight gain was calculated for each group at each time point (Figure 4). All rats gained 16\%-17\% of their body weight by the end of the 3-week follow-up period: the $\gamma-\mathrm{Fe}_{2} \mathrm{O}_{3} \sim \mathrm{PEG}$ group gained $16 \% \pm 2 \%$, the $\gamma-\mathrm{Fe}_{2} \mathrm{O}_{3} \sim \mathrm{HSA}$ group $18 \% \pm 1 \%$, the $\gamma-\mathrm{Fe}_{2} \mathrm{O}_{3} \sim \mathrm{HSA}-\mathrm{MTX}$ group $17 \% \pm 1 \%$, and the $\gamma-\mathrm{Fe}_{2} \mathrm{O}_{3}$ group $18 \% \pm 1 \%$. There were no significant

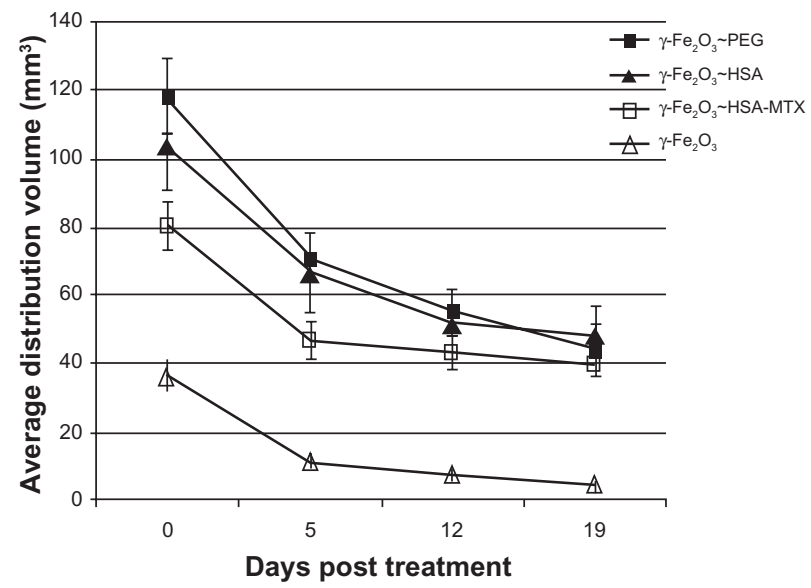

Figure 2 Nanoparticle distribution volumes in rat brain as a function of time post-CED treatment for the 4 treatment groups. The distribution volumes were calculated from gradient-echo magnetic resonance images acquired immediately post treatment and 5,12 , and 19 days thereafter.

Abbreviation: CED, convection-enhanced delivery; PEG, polyethylene glycol; HSA, human serum albumin; MTX, methotrexate.
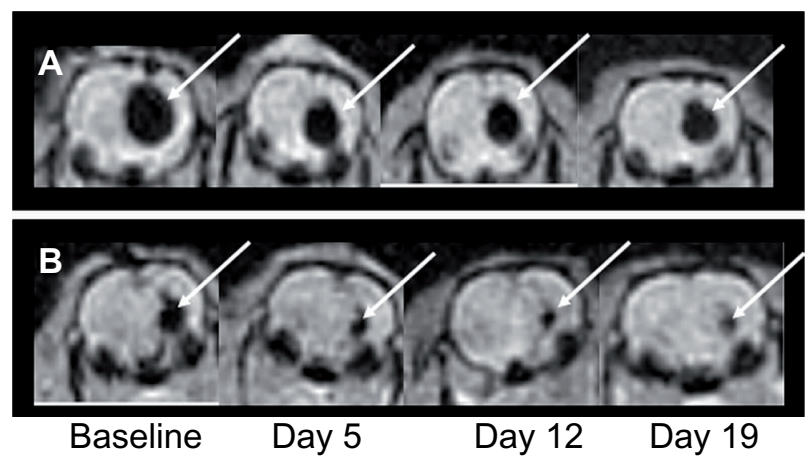

Figure 3 Gradient-echo magnetic resonance images of nanoparticle distributions as a function of time for a rat treated with $\gamma-\mathrm{Fe}_{2} \mathrm{O}_{3} \sim \mathrm{HSA}-\mathrm{MTX}(\mathbf{A})$ and a rat treated with $\gamma-\mathrm{Fe}_{2} \mathrm{O}_{3}(\mathbf{B})$.

differences among any of the groups, suggesting no apparent toxicity.

Twelve rats died of the anesthesia administered for the MRI follow-ups. This high rate of mortality is attributed to the repeated anesthesia and not to treatment-related toxicity, since all deaths occurred within a few hours of anesthesia administration (the rats never woke up afterwards). In the $\gamma-\mathrm{Fe}_{2} \mathrm{O}_{3} \sim$ PEG group, one rat died following the 2-week follow-up MRI and two rats died following the 3-week MRI. In the $\gamma-\mathrm{Fe}_{2} \mathrm{O}_{3} \sim \mathrm{HSA}$ group, one rat died following the 1-week follow-up MRI, one rat died following the 2-week follow-up and one rat died following the 3-week follow-up. In the $\gamma-\mathrm{Fe}_{2} \mathrm{O}_{3} \sim \mathrm{HSA}-\mathrm{MTX}$ group, one rat died following the 2-week follow-up MRI and two rats died following the 3-week MRI follow-up. In the $\gamma$ - $\mathrm{Fe}_{2} \mathrm{O}_{3}$ group, 1 rat died after the 1-week MRI follow-up and two rats died following the 3-week MRI follow-up. Since there was no difference in mortality among the three groups, and all deaths occurred soon after administration of the anesthesia, it was concluded that mortality was not treatment related.

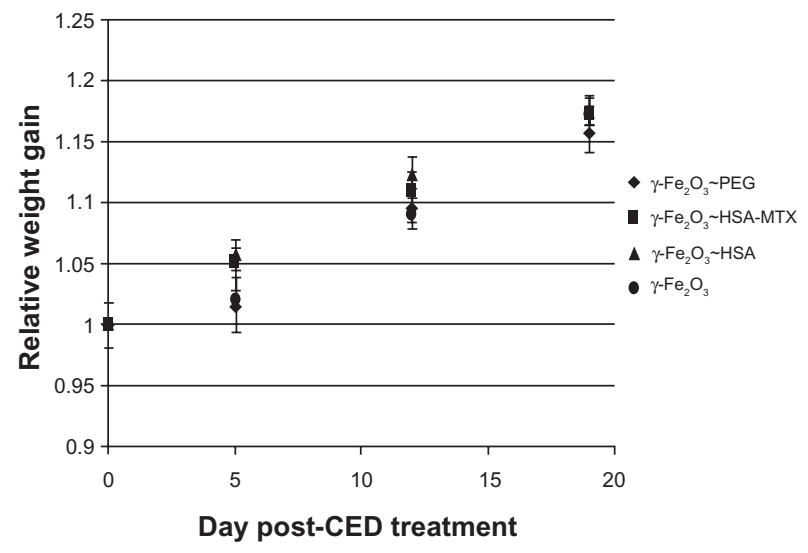

Figure 4 Average relative rat weight gain for each treatment group as a function of time post-CED treatment for the 4 treatment groups.

Abbreviation: CED, convection-enhanced delivery; PEG, polyethylene glycol; HSA, human serum albumin; MTX, methotrexate. 


\section{Discussion}

CED is a novel approach to directly deliver drugs into brain tumors, producing a high concentration of the drug over large volumes within the tumor, while avoiding systemic toxicity. However, initial clinical experience indicates that the main pitfalls of this methodology are the difficulties in forming efficient convection, limited monitoring, and nonspecific toxicity. Efficient CED is currently limited to small molecules. The present study was aimed at applying our increased efficacy and imaging methodologies to enable the efficient CED of drug-loaded nanoparticles, leading the way for therapeutic agents and/or drug carriers that until now were considered inappropriate for convection treatment. Nanoparticles as carriers may enable real-time depiction of the drug distribution, slow drug release, delivery of larger therapeutic agents, and allow targeted drug delivery.

The superparamagnetic maghemite nanoparticles we used are optimal for clinical application due to the uniform nanoparticle population of very narrow size distribution. In order to optimize for the increased efficacy of the nanoparticle distribution in the brain, and in order to obtain efficient binding of the MTX without compromising the efficacy of the drug, coating with both PEG and HSA was studied.

The particles not containing drug $-\gamma-\mathrm{Fe}_{2} \mathrm{O}_{3} \sim \mathrm{PEG}$, $\gamma-\mathrm{Fe}_{2} \mathrm{O}_{3} \sim \mathrm{HSA}$ and the naked $\gamma-\mathrm{Fe}_{2} \mathrm{O}_{3}$ particles showed no significant toxicity in vitro, implying that these particles may be used as drug carriers. The particles in which MTX was bound via PEG, $\gamma$ - $\mathrm{Fe}_{2} \mathrm{O}_{3} \sim$ PEG-MTX, showed a low cell-kill efficiency with a wide range of variability, suggesting poor binding of the drug. The nanoparticles in which MTX was bound via a covalent bond to HSA, $\gamma-\mathrm{Fe}_{2} \mathrm{O}_{3} \sim \mathrm{HSA}-\mathrm{MTX}$, showed a slightly lower cell-kill efficacy relative to that of the free MTX, likely caused by the uptake difference as the bulkier $\gamma-\mathrm{Fe}_{2} \mathrm{O}_{3} \sim \mathrm{HSA}-\mathrm{MTX}$ nanoparticles may not be taken up as easily as the free MTX at the same concentration, or by the fact that the MTX may need to be cleaved from the nanoparticles before it shows the toxicity. This is in agreement with the literature, ${ }^{12,14}$ suggesting it may be a good candidate for the delivery of MTX by CED. In one of these studies, ${ }^{14} \mathrm{MTX}$-conjugated nanoparticles were also shown to have targeting specificity for the same tumor cell line (9L rat glioma) used in our study, over a healthy cell line (Cultured Pulmonary Artery Endothelial).

The goal of the in vivo study was to assess the distribution efficacy of the different nanoparticles, to test for toxicity, and to evaluate the clearance time from the tissue. The distribution efficacy of all the coated particles was found to be efficient and significantly higher than that of the naked particles. The PEG coating seemed to provide a similar distribution efficacy to that of the HSA coating since there was no significant difference between the distribution volumes of the $\gamma-\mathrm{Fe}_{2} \mathrm{O}_{3} \sim \mathrm{PEG}$ and the $\gamma-\mathrm{Fe}_{2} \mathrm{O}_{3} \sim \mathrm{HSA}$ nanoparticles. On the other hand, the $\gamma$ - $\mathrm{Fe}_{2} \mathrm{O}_{3} \sim \mathrm{HSA}$-MTX had slightly lower distribution volumes. There was no significant difference between those and the distribution volumes of the HSA particles without the MTX, but there was a significant difference when comparing the $\gamma-\mathrm{Fe}_{2} \mathrm{O}_{3} \sim \mathrm{PEG}$ with the $\gamma-\mathrm{Fe}_{2} \mathrm{O}_{3} \sim \mathrm{HSA}-\mathrm{MTX}$, suggesting that the MTX binding may somewhat decrease the distribution efficacy of the particles. However, the distribution volume of the $\gamma-\mathrm{Fe}_{2} \mathrm{O}_{3} \sim \mathrm{HSA}-\mathrm{MTX}$ particles was more than twice that of the naked particles, implying that these are good candidates for CED treatment. The clearance time of the latter seems to be somewhat slower than that of the other coated particles, resulting in very similar distributions 19 days post treatment.

In this study, we have demonstrated the feasibility of binding an anti-cancer agent, MTX, to biodegradable maghemite nanoparticles, while preserving the penetration of the particles into the cells, and the efficacy of the drug against cancer cells. In addition, we have shown that the chosen formulation provides efficient distributions of the particles in rat brains, depicted by MRI in real time, with no apparent toxicity, and that the clearance time of the particles is long, enabling slow drug release.

\section{Acknowledgments}

This research was funded by The Goldhirsh Foundation Brain Tumor Research Awards Program. The authors thank Louise Braverman for her help in editing the final manuscript.

\section{Disclosure}

Some of the authors are inventors of relevant patents. The authors have no other conflicts of interest to declare in relation to this work.

\section{References}

1. Ohata K, Marmarou A. Clearance of brain edema and macromolecules through the cortical extracellular space. J Neurosurg. 1992; 77(3): 387-396.

2. Bobo RH, Laske DW, Akbasak A, Morrison PF, Dedrick RL, Oldfield EH. Convection-enhanced delivery of macromolecules in the brain. Proc Natl Acad Sci U S A. 1994;91(6):2076-2080.

3. Lieberman DM, Laske DW, Morrison PF, Bankiewicz KS, Oldfield EH. Convection-enhanced distribution of large molecules in gray matter during interstitial drug infusion. J Neurosurg. 1995;82(6):1021-1029.

4. Morrison PF, Laske DW, Bobo H, Oldfield EH, Dedrick RL. High-flow microinfusion: tissue penetration and pharmacodynamics. Am J Physiol. 1994;266(1 Pt 2):R292-R305. 
5. Chen MY, Lonser RR, Morrison PF, Governale LS, Oldfield EH. Variables affecting CED to the striatum: a systematic examination of rate of infusion, cannula size, infusate concentration, and tissue-cannula sealing time. J Neurosurg. 1999;90(2):315-320.

6. Chen ZJ, Broaddus WC, Viswanathan RR, Raghavan R, Gillies GT. Intraparenchymal drug delivery via positive-pressure infusion: experimental and modeling studies of poroelasticity in brain phantom gels. IEEE Trans Biomed Eng. 2002;49(2):85-96.

7. Mardor Y, Rahav O, Zauberman Y, et al. Convection-enhanced drug delivery: increased efficacy and magnetic resonance image monitoring. Cancer Research. 2005;65(15):6858-6863.

8. Perlstein B, Ram Z, Daniels D, et al. Convection-enhanced delivery of maghemite nanoparticles: increased efficacy and MRI monitoring. Neuro Oncol. 2008;10(2):153-161.

9. Vezmar S, Becker A, Bode U, Jaehde U. Biochemical and clinical aspects of methotrexate neurotoxicity. Chemotherapy. 2003;49(1-2): $92-104$.

10. Banerjee D, Mayer-Kuckuk P, Capiaux G, Budak-Alpdogan T, Gorlick R, Bertino JR. Novel aspects of resistance to drugs targeted to dihydrofolate reductase and thymidy late synthase. Biochim Biophys Acta. 2002;1587(2-3):164-173.

11. Wosikowski K, Biedermann E, Rattel B, et al. In vitro and in vivo antitumor activity of methotrexate conjugated to human serum albumin in human cancer cells. Clin Cancer Res. 2003;9(5):1917-1926.

12. Kohler N, Sun C, Fichtenholtz A, Gunn J, Fang C, Zhang M. Methotrexate-immobilized poly(ethylene glycol) magnetic nanoparticles for MR imaging and drug delivery. Small. 2006;2(6):785-792.

13. Paliwal R, Rai S, Vyas SP. Lipid drug conjugate (LDC) nanoparticles as autolymphotrophs for oral delivery of methotrexate. J Biomed Nanotechnol. 2011;7(1):130-131.

14. Young KL, Xu C, Xie J, Sun S. Conjugating methotrexate to magnetite $(\mathrm{Fe}(3) \mathrm{O}(4))$ nanoparticles via trichloro-s-triazine. J Mater Chem. 2009; 19(35):6400-6406.

15. Jordan A, Wust P, Fahling H, John W, Hinz A, Felix R. Inductive heating of ferrimagnetic particles and magnetic fluids: physical evaluation of their potential for hyperthermia. Int J Hyperthermia. 1993; 9(1):51-68

16. Margel S, Tenanbaum M, Fisher I. Methyl $\alpha$-(hydroxymethyl)acrylate microspheres: design, synthesis, characterization, and use. $J$ Colloid Interface Sci. 1992;150(1):22-35.

17. Ugelstad J, Soderberg L, Berge A, Bergstrom J. Monodisperse polymer particles - a step forward for chromatography. Nature. 1983; 303(5912):95-96.

18. Arshady R. Microspheres for biomedical applications: preparation of reactive and labelled microspheres. Biomaterials. 1993;14(1): $5-15$.

19. Kreuter J. Peroral administration of nanoparticles. Adv Drug Deliv Rev. $1991 ; 7: 71-86$
20. Schwarz C, Mehnert W, Lucks JS, Muller RH. Solid lipid nanoparticles for controlled drug delivery I: production, characterization and sterilization. J Control Release. 1994;30:83-96.

21. Pines M, Margel S. Polyacrolein microspheres as a new solid phase for radioimmunoassay. J Immunoassay. 1986;7(1-2):97-111.

22. Frank H, Loewe R, Loewe C, et al. Efficacy of thrombolytic therapy in pulmonary embolism determined by MION-enhanced MRA: an experimental study in rabbits. Invest Radiol. 1998;33(12):853-857.

23. Margel S, Gura S. Nucleation and growth of magnetic metal oxide nanoparticles of controlled size distribution and its use. EC 1088315 (2003); Israel 139638 (2006).

24. Anderson SA, Glod J, Arbab AS, et al. Noninvasive MR imaging of magnetically labeled stem cells to directly identify neovasculature in a glioma model. Blood. 2005;105(1):420-425.

25. Margel S, Lublin-Tennenbaum T, Gura S, et al. Synthesis and characterization of nano- and micron-sized iron oxide and iron particles for biomedical applications. In: Zborowski M, Chalmers JJ, editor. Laboratory techniques in biochemistry and molecular biology. Vol. 32. Amsterdam: Elsevier; 2008:119-157.

26. Taupitz M, Wagner S, Schnorr J, et al. Phase I clinical evaluation of citrate-coated monocrystalline very small superparamagnetic iron oxide particles as a new contrast medium for magnetic resonance imaging. Invest Radiol. 2004;39(7):394-405.

27. Peng X, Qian X, Mao H, et al. Targeted magnetic iron oxide nanoparticles for tumor imaging and therapy. Int J Nanomedicine. 2008;3(3): 311-321.

28. Wosikowski $\mathrm{K}$, Biedermann E, Rattel B, et al. In vitro and in vivo antitumor activity of methotrexate conjugated to human serum albumin in human cancer cells. Clin Cancer Res. 2003;9(5):1917-1926.

29. Cho K, Wang X, Nie S, Chen Z, Shin DM. Therapeutic nanoparticles for drug delivery in cancer. Clin Cancer Res. 2008;14(5):1310-1316.

30. Patel MM, Goyal BR, Bhadada SV, Bhatt JS, Amin AF. Getting into the brain: approaches to enhance brain drug delivery. CNS Drugs. 2009; 23(1):35-58.

31. Bidros DS, Liu JK, Vogelbaum MA. Future of convection-enhanced delivery in the treatment of brain tumors. Future Oncol. 2010;6(1): 117-125.

32. Allard E, Passirani C, Benoit JP. Convection-enhanced delivery of nanocarriers for the treatment of brain tumors. Biomaterials. 2009; 30(120):2302-2318.

33. Bradford MM. A rapid and sensitive method for the quantification of microgram quantities of protein utilizing the principle of protein-dye binding. Anal Biochem. 1976;72:248-254.

34. Ziv O, Margel S. Synthesis and characterization of thrombin conjugated $\gamma$-Fe2O3 magnetic nanoparticles for hemostasis. Advanced Engineering Materials. 2009;11(120):B251-B260.

35. Conover WJ. Practical nonparametric statistics, 2nd ed. New York: John Wiley \& Sons; 1980:225-226.
International Journal of Nanomedicine

\section{Publish your work in this journal}

The International Journal of Nanomedicine is an international, peerreviewed journal focusing on the application of nanotechnology in diagnostics, therapeutics, and drug delivery systems throughout the biomedical field. This journal is indexed on PubMed Central, MedLine, CAS, SciSearch ${ }^{\circledR}$, Current Contents ${ }^{\circledR} /$ Clinical Medicine,

\section{Dovepress}

Journal Citation Reports/Science Edition, EMBase, Scopus and the Elsevier Bibliographic databases. The manuscript management system is completely online and includes a very quick and fair peer-review system, which is all easy to use. Visit http://www.dovepress.com/ testimonials.php to read real quotes from published authors. 